\title{
Crowdsourcing aimed at value innovation
}

\author{
Teresa Cristina Monteiro \\ Martins \\ University of Lavras \\ teresacristina.ufla@gmail.com
}

\author{
André Luiz Zambalde \\ University of Lavras \\ zamba@dcc.ufla.br
}

\author{
Paulo Henrique de Souza \\ Bermejo \\ University of Brasilia \\ paulobermejo@next.unb.br
}

\begin{abstract}
We aim to relate the theories of the blue ocean [1] and the wisdom of the crowds to answer the research question, "Can crowdsourcing contribute to the generation of innovation of value?" For this purpose, we searched the literature and the Internet for information on the four businesses (iStockphoto, Web Junk 20, InnoCentive, and Amazon Mechanical Turk [AMT]) used by Howe [2] to propose the term crowdsourcing. For each business, we identified the characteristics that would allow us to classify it as crowdsourcing at the present time. In this first analysis, we concluded that currently, Web Junk 20 would not be classified as crowdsourcing. In the second analysis, we looked for the four businesses' attributes that were capable of generating innovation of value. We concluded that iStockphoto, InnoCentive, and AMT had common features that generated value innovation and could be grouped into the reduce, eliminate, create, and elevate matrix, according to the blue ocean.
\end{abstract}

\section{Introduction}

The blue ocean theory and the crowdsourcing concept have recently reached the 10th year since their formulation and are considered strategic in the processes of organizational innovation. The first is used to create new innovative markets [1], and the second is applied to open the processes of business innovation [2]. The blue ocean refers to a cycle of continuous development of business models, which are transformed to meet new social demands, as well as to appropriate new technologies for generating new demands and transforming the market. According to this theory, organizations are always evolving, creating, or reinventing businesses, hence generating blue oceans to get rid of the competition [2].

The factors that have recently transformed markets and companies are the advancement of technology and the increasing complexity and networking of organizations. In response to this new configuration of organizations, open innovation methodologies have emerged, which take advantage of the benefits of technologies to search for ever-broader networking solutions to drive business innovation. Thus, similar to a cycle, open innovation also causes changes in organizational structures, especially in relation to the opening of the research and development (R\&D) process. Crowdsourcing is an open innovation methodology that is widely used in this process, which means outsourcing tasks to a crowd. The term crowdsourcing was initially used by Howe [2] to characterize some companies that emerged in the early 2000s and used the Internet to modify their business models to become more open structures based on the participation of large numbers of people. The business model cited by Howe [2] was considered innovative. Today, over a decade after the term was coined, it is possible to verify if the businesses that used crowdsourcing generated some innovation of value to the market. In one of his recent articles, Henry Chesbrough, the leading author of publications about open innovation, points to the lack of open innovation in strategic studies [3] as a gap in open innovation research. According to the author, open innovation should be viewed not only as a methodology for the generation of innovative knowledge but also in the aspect of the new strategic relationships that are established among organizations. To relate the themes of open innovation and strategy, we aim to explore the value innovation that occurred in businesses that used crowdsourcing and to answer the following research question: "Can crowdsourcing contribute to the generation of innovation of value?" The study subjects that we used were the pioneering crowdsourcing businesses (iStockphoto ${ }^{1}$ Web Junk 20, InnoCentive ${ }^{2}$,

\footnotetext{
${ }^{1}$ https://www.istockphoto.com/

${ }^{2}$ https://www.innocentive.com/
} 
and Amazon Mechanical Turk [AMT] $]^{3}$ ) cited by Howe [2] in the article where he coined the term crowdsourcing.

We studied the four businesses by reviewing the literature in which they were cited and browsing these companies' websites. We used the criteria listed by Estellés-Arolas and González-Ladrón-De-Guevara [4] to characterize the businesses cited as crowdsourcing and Brabham's [5] criteria to classify them according to the type of crowdsourcing. Next, for each of the businesses, we investigated whether there was any reduction in costs or increase in added value as the determining factors that generate value innovation [1]. We also examined which attributes were reduced, eliminated, elevated, or created to determine business value innovation, as well as identified the focus, singularity, and consistent message of each business [1]. Based on this research and the information obtained, we outlined the value evaluation matrix of crowdsourcing and discussed both potentials and limitations of using crowdsourcing from the perspective of the strategy for creating new markets.

\section{Value Innovation and the Blue Ocean Strategy}

For a company to remain in the market, operational effectiveness is insufficient; strategic positioning is needed [6]. Operational effectiveness is related to being better than rivals in performing similar activities, while strategic positioning means performing activities differently from those of rivals [7]. Value innovation emerges when attention is shifted from the supply side to the demand side, from overcoming competition to the creation side of customer value. Rather than merely shifting the focus to the demand side, it is important to note that value innovation goes beyond the recombination of the means of production proposed by Schumpeter; it is a reconstruction of the business boundaries by the creation of a new market space called a blue ocean [1]. Value innovation is what Kim and Mauborgne [1] call the cornerstone for reaching the blue ocean. These authors coined the term blue ocean to represent the unexplored market where it is possible to arrive by creating a demand. When the supply starts to surpass the demand, it is necessary to create a new demand, that is, an unexplored market; in this context, the blue ocean is formed. The major difference between oceans is how to approach strategy. The blue ocean goes against the very origin of the term strategy, which is the structure of the headquarters where it is presumed to be used to combat opponents. In contrast, the blue ocean strategy aims to avoid competition by offering truly innovative products and services to society, achieved through value innovation

\footnotetext{
${ }^{3}$ https://www.mturk.com/
}

[1].

Value innovation is about creating new markets by reducing costs and increasing the added value to buyers. The value to buyers increases as companies expand and create attributes that have never been offered by the industry. Over time, as the product offered has a higher value to the buyer, the tendency is for sales to grow and a larger economy to be established, determining the natural reduction of costs [1]. Value innovation also presents market dynamics that differ from conventional technological innovation. Generally, when a technological innovation is launched, the company charges for it the highest price that the consumer is able to pay in order to cover the innovation cost. In the blue ocean strategy, whose goal is non-rivalry, it is interesting that companies seek to win over the mass of target buyers since the innovation launch and expand the market size by offering much higher value and lower coasts [1].

According to Kim and Mauborgne [1], to achieve value innovation, an organization's attributes overcome the competition through a strategy of market creation. To do so, the authors propose the four-action model that answers these questions: (1) What attributes of the business can be considered dispensable by the industry and should be eliminated? (2) What attributes are considered important but no longer generate value and must therefore be reduced? (3) What attributes should be elevated to correct the constraints imposed by the industry on customers? (4) What attributes should be created to add value for new buyers and create new demand?

The expected result of this process is a single value curve, which presents the organization's focus, uniqueness, and consistent message. These three requirements are indispensable for value innovation: focus to highlight the attributes that differentiate the organization, clearly showing its strategic profile; singularity to present a value curve that differs from those of the old rivals; and a consistent message to affirm the company's strengths in a few words and an efficient manner.

\section{Crowdsourcing: From Collective Intelligence to the Web}

Howe [2] coined the term crowdsourcing to designate a form of using a crowd by outsourcing an activity to a broad group of people in the expectation of finding persons capable of generating more efficient results than those found in the organization. Although relatively new, the theme refers to older theories stating that the crowd may be smarter than experts. Lévy's theory of collective intelligence is considered one of the forerunners of the crowdsourcing concept [8]. According to the author, intelligence is distributed everywhere because it is the result of the set of wisdom and tacit knowledge that each individual possesses. Through the technologies, 
especially those that allow the organization to join in networks, the intelligence can be organized in cyberspace, creating a kind of collective consciousness that is unique around a certain theme.

The usefulness of this collective intelligence is demonstrated by Surowiecki [9], who conceptualizes it as the wisdom of the crowds. The author cites several examples of how the average crowd's views may be more efficient at solving a particular problem than a specialist's sole opinion. The author argues that the best decisions are the results of disagreements and discussions, not of consensus and commitment, so he believes that under the proper circumstances, groups' opinions that are considered collectively may be more intelligent than the single opinion of the most intelligent individual in the group [9].

According to Howe [2], crowdsourcing is a new approach to accessing less costly and decentralized labor (although it is not clearly conceptualized in crowdsourcing) in order to create content and solve problems, including collaborating in the R\&D process of companies. Another well-known author in the field is Brabham [5], who presents crowdsourcing as a challenge presented to an online community, aiming at capturing information from the masses and transforming it into useful knowledge. Brabham classifies crowdsourcing by its objectives: to discover and manage knowledge, to search for existing solutions that are not yet known by the organization that seeks, to creatively generate innovative ideas, and to distribute tasks that require human intelligence [5].

Based on these two main authors' (Howe and Brabham) definitions of crowdsourcing and 40 others, Estellés-Arolas and González-Ladrón-De-Guevara [4] identify the following characteristics: (a) outsourcing to a clearly defined crowd, (b) whose mission is the execution of a task with a clear objective. (c) In return, a reward is offered to the crowd. (d) The institution or the person proposing crowdsourcing is clearly identified by the participants, and the advantages that the applicant wishes to receive through crowdsourcing are also clearly defined. (e) Crowdsourcing should occur online and be participatory. (f) It should use an open call with variable deadlines $(\mathrm{g})$ through the Internet.

\section{Methodology}

We relate two theories - wisdom of the crowds [9] and blue ocean [1] - openly, without a rigid protocol for writing this article. We present the wisdom of the crowds to support the crowdsourcing concept and discuss the blue ocean theory to present value innovation as a strategy for reaching untapped markets. To verify the possible value innovation resulting from the use of the crowdsourcing methodology, we analyze the four businesses mentioned by Howe.
To gather information on the four businesses, we conducted a search in the Science Direct database and on the companies' websites. The names of the businesses under study were used as keywords for searching the articles in the scientific database. The search returned 32 articles on iStockphoto, 35,367 on InnoCentive; none on Web Junk 20, and 2,323 on AMT. Due to the large number of articles on AMT, we chose to search for the term only in the abstracts, titles, and keywords, resulting in 167 articles. We found that our search using the term InnoCentive returned articles with the word innocent. To correct this fault, we used the search string "innocentive AND crowdsourcing"which generated only 116 articles. We chose the Science Direct database because it was the only one that returned significant numbers of articles on the subjects.

After collecting the articles, we read their titles to filter the articles to only those describing cases of the use of crowdsourcing by the companies under study and the main aspects of their businesses. After this procedure, we selected 5 articles with case studies on AMT, 10 on iStockphoto, and 9 on InnoCentive. We performed the analysis of the articles in two stages: the first one to characterize crowdsourcing and the second one to evaluate what attributes of value innovation were present in the mentioned businesses. Our objective was to find in the articles the characteristics demonstrating that these deals were based on the crowdsourcing methodology and that the evidence of these valuable innovations led these businesses to navigate the blue ocean. In the first stage, we used the criteria established by Estellés-Arolas and GonzálezLadrón-de-Guevara [4] as fundamental for characterizing crowdsourcing and classified the businesses by their objectives, according to Brabham's [5] typology. After this classification and the identification of the types of crowdsourcing, we discussed whether each crowdsourcing brought some innovation of value to the cited companies. To verify if there was innovation of value, we identified the following attributes per business: (1) Is there singularity, focus, and a consistent message? (2) Has the business resulted in increased value added or reduced costs for each company that implemented it? (3) What attributes have been reduced, eliminated, elevated, or created to achieve value innovation?

We carried out all the analysis by means of the secondary data collected from the literature that investigated the cases cited by Howe [2] and based on the companies' websites. The research took place from June to August 2017.

\section{Cases of Value Innovation}

Value innovation is the result of reduced costs and increased value added. To achieve value innovation, it is necessary to rethink an organization's business in 
order to elaborate on a new value curve relating to which attributes should be reduced, eliminated, created, or elevated [2].

When Howe [2] coined the term crowdsourcing, he underscored the importance of open innovation and exemplified crowdsourcing by using the cases of four companies: iStockphoto, Web Junk 20, InnoCentive, and AMT. Currently, it is possible to arrive at a better diagnosis of the value innovation generated by these companies, that is, how they modified the markets where they operated and which attributes were responsible for these changes. In the following sections, we describe the market changes caused by these companies, the strategies used to achieve these changes, the value added by them for the consumers of their products and services, and the cost reduction obtained by each of them. After this individual diagnosis, we present a synthesis of the attributes that are common to these companies and illustrate the characteristics of the crowdsourcing methodology that impact on the generation of value.

\section{iStockphoto}

The first crowdsourcing company cited by Howe [1], iStockphoto was founded in May 2000, an innovative photography agency fostered by a community of amateur photographers called iStockers. The innovative business works as follows: iStocker uploads a contributor's images, animations, and video clips on the site. Customers visit the site and choose and download media from that stock [10]. Amateur photographers earn small profits from every download of their images, and iStockphoto takes another fraction of the profits. The significant value innovation brought by the company lies in the possibility of offering a huge database at an affordable price, less costly than that of any other competing company [11]. To add to the collection of this database, the company makes public calls open, and the community provides solutions by uploading its creative content. Thus, iStockphoto attracts customers who select their desired inventory, and users and iStockphoto earn money from the transactions.

It is possible to characterize the business as crowdsourcing, following the requirements established by Estellés-Arolas and González-Ladrón-De-Guevara [4]. The task of crowdsourcing is clearly defined: bringing together the largest number of images to offer site customers an incredible collection at a reasonable price. The crowd is also clearly defined and comprises users who sign an association agreement online where suppliers and buyers of images accept the company's standardized trading conditions before releasing content from the site. The profile of the crowd participating in iStockphoto has been studied by Brabham [5], who classifies the members as elite web users who mostly belong to the middle and the upper classes, are educated, and have high-speed Internet connections at home.

The revenue received by the platform's content producers ranges from $20 \%$ to $40 \%$ of the price paid by the image buyer, but these values are clearly set on the website prior to trading. The crowdsourcer in this case is the iStockphoto company itself, which receives a percentage of each transaction brokered through the site. The platform is considered a venue for a permanently open call for sending new media to the database and the entire transaction, which is performed online. Characterizing the business model as crowdsourcing makes it possible to classify it, according to Brabham's [5] typology, as the distribution of tasks that require human intelligence. In this process, the task of assembling a large number of images with different themes is divided into a large group. Thus, the task of each group member is simple and requires a low level of individual creativity since the value innovation lies in the set of images, not in the production of each one. Cost reduction, one of the pillars of value innovation, is realized in the expansion of the photo bank and the pool of suppliers. Suppliers who were previously limited to professional photographers now include amateur photographers, such as housewives, students, and professionals who engage in photography as a hobby and settle for small payments for their jobs. As a result, the number of people available to perform the task of assembling quality images increases, and professional photographers tend to accept lower compensation values for their images. On the other hand, these professionals also gain an advantage by having a greater space for publicizing their works and a site to intermediate the negotiation of the sale of their images.

The added value of the products and the services offered by iStockphoto is represented by the availability of free or affordable content to the community, its focus on mediating the transaction between the content-producing crowd and the buyers of its images and videos, as well as the expansion of the number of potential buyers with the worldwide and online availability of the image bank. As a result, iStockphoto caused disruption by launching a new business model for the sale and the licensing of images, called microstock, in 2000. The microstock brings together a wide range of images, obtained through the collaboration of the crowd, and offers it on the global market at more affordable coasts. It is a trend that takes advantage of the general population's greater access to knowledge and tools of photography, as well as the greater number of people who access the Internet and search for ways to make money. In this case, the value innovation that has occurred is in line with Kim and Mauborgne's [1] argument that the new strategy must create value for customers and other buyers (whether customers or not customers), as well as generate profits for the company and motivate 
people (be they employees, business partners, or the general public) to embrace and execute the new strategy with enthusiasm and commitment, characteristics that can be identified throughout the history of the business.

Ye and Kankanhalli [12] show that innovation is attributed to different motivations so that people can contribute to the platform. In contrast to conventional work, whose reward is monetary only, the platform offers skill enhancement, the pleasure of joining, and a solid reputation among peers.

Howe's [1] presentation of iStockphoto's business as successful crowdsourcing shows that as soon as iStockphoto was created, the stock industry lined up against it. In 2006, Getty Images, the then leading producer of images of publicity, bought iStockphoto for $\$ 50$ million. Consequently, iStockphoto's revenue grew by about $14 \%$ a month, and it was expected to license about 10 million images in 2006. According to the company's website, 70 million images are currently available. The three pillars of value innovation can also be identified in the company's new strategy for selling images. The business focuses on the intermediation between photographers and professionals who require image content for marketing and other activities. This activity develops in a unique way by offering advertising materials at low costs and the possibility for any photographer, even an amateur, to disclose and sell one's materials. To sell its philosophy and to generate enthusiasm on the part of the multitude that stimulates the business, the company uses three key messages: (1) "Incredible stock. Flexible pricing." "Incredible collection. Flexible pricing." (2) "Your idea deserves the right image." (3) "Less searching. More finding." "Fewer searches. More results."

\section{Web Junk 20}

Created in 2004, Web 2.0 refers to the web as a platform where users interact to produce and exchange content on the network. Howe [2] used the term TV 2.0 to present the characteristics of television channels that allow their viewers to create the content that will be made available. The example cited as a pioneer of TV 2.0 is the weekly Web Junk 20 program, shown in 2006 by the American channel VH1, which aired 20 videos that the editors considered the funniest and most interesting ones uploaded on the Internet per week. When the program was launched, its creators considered it an innovation in relation to what the Internet channel YouTube offers its users, that is, the transmission of the videos on television-"everyone wants to be on TV" [1].

Based on the crowdsourcing definitions collected by Estellés-Arolas and González-Ladrón-De-Guevara [4], when Web Junk 20 searches for ready-made videos on the Internet for TV viewing, this action does not fit crowdsourcing. The reason is that in this case, there is no online public call. However, when a video contest is held, even if the reward is not necessarily monetary, there is a public call, with a clear reward for participants, which is the opportunity to appear on TV. Other attributes that classify the initiative as crowdsourcing is that the crowd is also defined among the viewers who register on the site, and the crowdsourcer, which is the TV station, is also clearly identified for the participants. Web Junk 2.0's searches for already existing content, which until then was not known to the organization (as in the case of iStockphoto), can also be classified as crowdsourcing [5].

The program's business model has been widespread and has inspired several other models, such as contests in which candidates demonstrate their skills through home videos and are judged by other viewers, or the models stimulating the production of viral videos that are humorous enough to be aired on TV programs [1]. However, the TV 2.0 concept proposed by the author was not popularized because it failed to increase the use of content produced by the viewers. According to Howe [1], the cost reduction occurs only from the perspective of the producers since economic benefits are generated by the outsourcing of the content production. Because users do not pay for the specific service, that is, they do not pay to view the program specifically, cost analysis does not apply in this case. The added value to the users is the possibility for the masses' collaboration in creating their own programming. The use of these home videos led to a $40 \%$ increase in the number of viewers compared with the program shown at the same time on Friday the year before. However, a limitation is that the crowd may not be able or sufficiently interested in producing content that can guarantee the program's longevity [2].

Regarding the permanence of this business in the blue ocean, we can conclude that despite creating a value innovation by using the content produced by the crowd to create a TV program, the pioneering Junk Web 20 was short lived. The series lasted for only two years, succeeded by other projects that use the videos posted on the Internet as mass entertainment for the masses. What differs from the other crowdsourcing cases presented is that the content generated by the crowd is not owned by the company; the content is searched on different websites, not on a proprietary platform of the company. In analyzing this characteristic and the barriers to imitation presented by Kim and Mauborgne [1], this short-lived pioneerism can be explained by the fact that imitation did not require great efforts by the competitors, who had as facilitators the success achieved by the initiative reference, the low cost of investment, and the fact that neither great political, operational, or cultural changes in the organizations nor the development of new systems would be necessary because all content was already in the network. 


\section{InnoCentive Crowdstorming}

Howe [2] points out InnoCentive as a worldwide network of scientists that has altered the structure of the business R\&D sector. The author explains that InnoCentive involves crowdsourcing of ideas, in which companies such as Boeing, DuPont, and Procter \& Gamble (P \& G) pay fees to publish their scientific problems and disseminate them in a wide online network for anyone to have the opportunity to solve them in exchange for an award for the best idea [1]. Thus, the crowdsourcing proposed by InnoCentive can be classified as a creative production of innovative ideas or as the search for existing solutions that are not yet known to the organization concerned [5].

Following the requirements to be characterized as crowdsourcing [4], InnoCentive has a crowd of 375,000 people from different parts of the world and with different specializations, who are registered free on the platform. The tasks are the public calls on the Internet, called brainstorms, that work as global brainstorming to produce innovative ideas for solving technical problems, create new product lines, provide a new commercial application of a new product, or develop a marketing idea. Each challenge of ideas proposed on the platform offers a well-defined reward, whose value varies between $\$ 10$ and $\$ 200,000$ [13]. Although the rewards are clearly indicated to the participants, the crowdsourcing applicants have the option of not identifying themselves to avoid revealing their innovation intentions to competitors.

In contrast to the other crowdsourcing cases cited, InnoCentive has gone beyond creating a value innovation, having been created for companies to seek value innovation for their products, processes, or services, with the crowd's collaboration. This generation of value through the crowd's engagement is reported in some cases, narrated on the platform, and also quoted by Howe [1]. One of the examples cited by Howe [2] is the case of P \& G, which uses the InnoCentive platform to outsource part of its $R \& D$ process. According to Gassmann and Enkel [13], P \& $\mathrm{G}$ makes intensive use of the knowledge gained on the platform for its innovation process; in 2002, when it started using the platform, $10 \%$ of its new products, processes, or services came from the ideas generated on the platform. According to InnoCentive ${ }^{4}$, in 2017, the platform was present in more than 200 countries, with over 380,000 people registered as problem solvers. InnoCentive's business model has added value to some organizations' $R \& D$ process, proposing that this process should also be decentralized to the crowd

\footnotetext{
${ }^{4}$ https://www.innocentive.com/
}

by brainstorming via the Internet. The platform is a precursor to others that also challenge ideas for both public and private sectors, such as Ninesigma, created in 2006, and Mindmixer, created in 2010. The mentioned attributes add value to a business by offering the possibility of involving the company's customers in product development [13]. To achieve this goal, it is necessary to have a high level of external knowledge, without hiring, to obtain more innovation ideas for future licensing and patent purchase.

Thus, InnoCentive adds value to the $R \& D$ process of the companies that contract its service by offering a strategy to simplify and at the same time increase customer participation in the process of innovating the companies' businesses, adding legitimacy to the products and the services they offer [13]. The innovation cost can be reduced by the possibility of having more professionals think about the presented problem and being remunerated only for the best ideas.

The uniqueness of InnoCentive's launch lay in providing the environment for global brainstorming, reproduced in subsequent years by several other platforms, focused on public and private sector innovation [14]. InnoCentive focuses on producing open innovation for contracting companies, as declared in its core message: "Innovate with InnoCentive" ${ }^{5}$. This platform has also been used in the public sector, supporting the challenge.gov initiative; as a pioneer for governments, such as the Brazilian government that uses idea challenges to generate innovations in vocational and technological education and public health [15]; in the management of natural resources and sustainability [16]; and for the improvement of public security [17].

The open innovation and the cost reduction in $\mathrm{R} \& \mathrm{D}$ are evidenced in the articles that show the use cases of the platform. InnoCentive was initially created to generate innovations in the drug industry and is considered a precursor to the challenges on ideas that stimulate collective intelligence [18] and are innovative in integrating external sources of information for organizations [19]. In the pharmaceutical industry that requires constant investment in $R \& D$, the InnoCentive platform has been considered economically feasible for expanding the industry's innovation initiatives [19]. In the food industry, the platform is currently used to generate innovations in food production and quality [20].

\section{Amazon Mechanical Turk}

AMT is a relatively new Internet-based business model that helps companies find people to

\footnotetext{
${ }^{5}$ https://www.innocentive.com/
} 
accomplish tasks. In contrast to InnoCentive and iStockphoto, which look for specialized talent, AMT deals with carefully designed tasks that require minimal time from the participants who are therefore compensated with a small reward, from a few cents to a few dollars [21]. AMT calls these tasks HITs (human intelligence tracks) [1]. To propose tasks, companies or applicants use a platform interface and report a billing address located in one of the 30 countries where the platform is used.

The workers who set out to perform the tasks remain anonymous, identified by a participation code, and the AMT platform manages tasks and workers. The tasks are clearly presented on the platform. When a worker accesses the site, he or she finds a list of tasks that can be completed in a few minutes, such as translations, audio descriptions, software tests, or participation in opinion polls [22]. The validation of the tasks performed by other workers can also be considered a task, and the remuneration for each task is also clearly presented. As the tasks involve little complexity, the requesters pay small amounts as rewards for the execution. These amounts can be as low as $\$ 0.01$, and rarely is a job worth more than $\$ 1$. The quality of the execution of the tasks can also be controlled, and the workers can be filtered by the requester.

Similar to iStockphoto, AMT involves crowdsourcing of tasks, in which the crowd is recruited to perform tasks that have low complexity but need human intelligence [5]. Workers are identified by their codes and answer basic questions about their profiles. In this way, the crowd participating in a certain task can be pre-selected according to the recruiter's desired profile. Thus, experiments performed on the platform could be conducted only with the participation of women, for example, or only with the participation of people who have knowledge about a certain theme [22].

Launched in November 2005, the AMT platform is an innovative business model of outsourcing work through the network, in which the workers themselves report their income, and there are no formal contractual work relations. Although the literature points it out as a platform for the development of many tasks of low complexity, the main successful result of AMT is its new way of recruiting a convenience sample to carry out social science research, especially in the areas of psychology and cognition [23]. The application presents an innovation by bringing together the main elements needed to conduct research: an integrated participant compensation system, a wide and diverse group of participants, and a simplified interface that allows the study design, the recruitment of participants, and data collection [24]. For these reasons, it is considered one of the most widely used applications worldwide for the recruitment of participants with specific profiles for conducting behavioral research [25].

In 2006, when Howe [2] described AMT's crowdsourcing as an innovation in the distribution of tasks, he warned of possible problems with the quality of the tasks performed. The problem with the job quality is a challenge for which some alternatives have been proposed, such as a more careful assessment of workers, for example, the one proposed by Ipeirotis [26]. Problems about labor relations also limit the use of AMT and raise questions about the ethical aspects related to the use of crowdsourcing [27].

Despite these issues, the platform lists a number of success stories, such as Acxiom, a US technology and marketing service company that (according to AMT) reduced its costs by $50 \%$ by outsourcing character transcription as a test to verify that the company's optical recognition system remains effective. Another case of cost reduction through outsourcing, presented by AMT, is the use of the crowd for translations, such as those commissioned by the Advanced Defense Research Projects Agency, which uses AMT to build a data bank to translate dialects and informal messages originally written in Arabic into English.

Some case studies of the use of AMT allow us to identify as its main added value the possibility of quickly and inexpensively recruiting experts in a certain area of interest. Even today, AMT is considered a useful tool in recruiting individuals with a history of certain diseases to examine the lesions and the psychological characteristics of these individuals so as to chart disease outbreaks [28, 29]. Other types of recruitment can be used, as follows: babies can participate in a study to identify the characteristics of a particular child audience [30], farmers can use AMT as part of a hierarchical system that uses images captured by a smartphone to identify weed images [31], and respondents can provide specific answers to questionnaires for academic research [32].

AMT's message is as follows: "We give businesses and developers access to a scalable, on-demand workforce. And the workers select from the thousands of tasks that are convenient for them to work." ${ }^{6}$ This makes clear the company's focus on the intermediation between contractors and workers for the performance of small tasks of low complexity that are not yet developed by computers. This approach also characterizes the singularity of AMT, a pioneer in the provision of this type of service.

\section{Value innovation through crowdsourcing}

\footnotetext{
${ }^{6}$ https://www.mturk.com/
} 
As presented by Kim and Mauborgne [1], value innovation is a result of reduced costs and increased value added. To achieve value innovation, it is necessary to rethink the organization's business in order to elaborate on a new value curve relating to which attributes should be reduced, eliminated, created, or elevated.

Regarding the four-action model-reduce, eliminate, create, and elevate-Figure 1 presents the typical actions of crowdsourcing-based businesses, enabling them to differentiate themselves from others and generate value innovation.

Figure 1. The model of the four actions in crowdsourcing

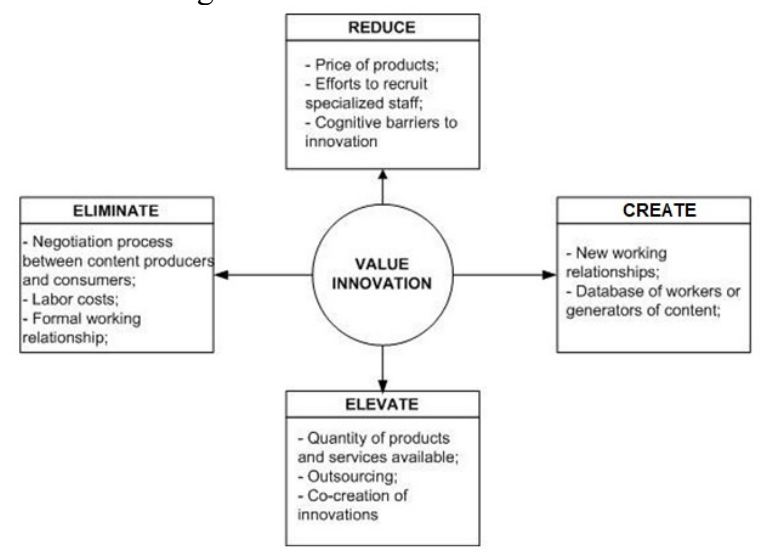

Source: the authors

The presented four-action model shows that for the studied cases, the main characteristic that differentiates the crowdsourcing-based businesses from other businesses of the same industry is the increase in outsourcing activities, whether small jobs or the generation of ideas. Because crowdsourcing is directed at the public, a large amount of content, whether ideas, tasks, or media, is often generated, which can lead to difficulties in filtering or even in the effective absorption of the generated content, a fact already raised by West et al. [33]. Another important aspect of the crowdsourcing business is the co-production of innovations, a strategy highlighted in both public and private sectors when creating products and services with greater legitimacy and levels of customer approval [34, 35].

At the other extreme are the attributes that should be reduced. It is clear that by reducing efforts to recruit skilled personnel to perform tasks and by increasing the number of people available to perform these tasks, the coasts of products and services tend to decrease. Cognitive barriers are also diminished, which means that by recruiting external staff for certain tasks or rethinking the innovation process, there is not much pessimism for maintaining the organization's status quo, which would be a major cognitive barrier, according to Surowieki [36].

The elements eliminate and create are closely related and highlight the elimination of formal labor relations and labor costs for the creation of new labor relations. Instead, a multitude can collaborate in finishing tasks without formal employment contracts that regulate the work hours, for example. In all of the businesses presented in this article, each contributor receives compensation for a completed task or for being the author of the best idea posted in the application. In this sense, it is important to consider also the existing relations between crowdsourcing and outsourcing studies, including thinking about what is possible to outsource to the crowd, even considering the ethical aspects of crowdsourcing.

Finally, crowdsourcing can be considered a value innovation that, through outsourcing, establishes new working relationships for the generation of significant content on the web that can be used, from the production of innovation ideas to the execution of small tasks. These new working relationships reduce the efforts related to the human resources involved in generating knowledge, which can decrease the innovation costs and consequently the coasts passed on to consumers.

\section{Conclusion}

We conclude that after more than ten years since the creation of the crowdsourcing concept, in which the concept was formalized and consolidated, all the examples cited by Howe [2] are considered crowdsourcing and can also be classified according to the Brabham [8] typology. However, the Web Junk 20 series cannot be considered crowdsourcing since it only takes advantage of content already produced and available on the network. The reason is that crowdsourcing necessarily involves a public and open call in which the usefulness of the information collected and the reward for participation are well defined. As for the creation of new markets from the presented businesses, all the companies have made innovations in the markets where they operate. These innovations are related to the expansion capacity of the service provider network that involves human intelligence, whether in the performance of small tasks (AMT), in the search for existing solutions or content (iStockphoto and Web Junk 20), or in the creative generation of innovative ideas and expert 
knowledge management (InnoCentive).

These attributes that characterize these businesses as crowdsourcing types are also those that have impacted value creation and cost reduction. In the case of iStockphoto, when the network crowd realizes that it can earn some money by selling its previously amateurish and unpretentious photographs, it tends to collaborate in creating a vastly more diverse stock of images than those of the agencies that hire professional photographers who work on demand. This and the other cases jointly answer the research question of how crowdsourcing can generate innovation of value.

Crowdsourcing allows the creation of a larger, more diversified, and low-cost stock compared with traditional methodologies that work on innovation in a closed way. The inventory can refer to the set of products that becomes available to the company, in addition to producing its products or content for itself, when it outsources this function to the crowd, as iStockphoto and Web Junk 20 have done. The set of experts gathered on idea delivery platforms, such as the InnoCentive pioneer, can also be understood as stock. These platforms lure researchers from a variety of fields, who, motivated by the reward, can conduct R\&D of a product for a company without even knowing or being employed by it. Even if they are not experts, the group of people determined to carry out the tasks proposed by companies that use AMT can also be considered a stock of labor, capable of developing services of low complexity.

In all cases, outsourcing results in cost reduction because the content, products, and services are produced without any employment links. Therefore, crowdsourcing represents a new strategy that does not officially hire experts to generate innovations. On the contrary, crowdsourcing looks for innovation or ideas for innovation from specialists or even non-specialists dispersed in the network of computers. This approach reduces costs, since the participants are remunerated for effective results, whether these are well-executed tasks or ideas with immense potential for innovation.

\section{References}

[1] Kim, W.C. and R. Mauborgne, Blue ocean strategy. If you read nothing else on strategy, read these best-selling articles. 2004: p. 71.

[2] Howe, J., The rise of crowdsourcing. Wired Magazine, 2006. 14(6): p. 1-4.

[3] Vanhaverbeke, W., et al., The importance of connecting open innovation to strategy, in Strategy and communication for innovation. 2017, Springer. p. 3-15.

[4] Estellés-Arolas, E. and F. González-Ladrón-De-Guevara, Towards an integrated crowdsourcing definition. Journal of Information Science, 2012. 38(2): p. 189-200.
[5] Brabham, D.C., Moving the crowd at Threadless: Motivations for participation in a crowdsourcing application. Information, Communication \& Society, 2010. 13(8): p. 1122-1145.

[6] Porter, M.E., What is strategy. Published November, 1996.

[7] Mintzberg, H., O Processo da Estratégia-4. 2006: Bookman Editora.

[8] Lévy, P. and C.I. da Costa, Tecnologias da inteligência, As. 1993: Editora 34.

[9] Surowiecki, James, and Mark P. Silverman. "The wisdom of crowds." American Journal of Physics 75.2 (2007): 190192.

[10] Neto, F.R.A. and C.A. Santos, Understanding crowdsourcing projects: A systematic review of tendencies, workflow, and quality management. Information Processing \& Management, 2018. 54(4): p. 490-506.

[11] Digout, J., et al., Crowdsourcing, outsourcing to obtain a creativity group. Arab Economic and Business Journal, 2013. 8(1-2): p. 6-15.

[12] Ye, H.J. and A. Kankanhalli, Solvers' participation in crowdsourcing platforms: Examining the impacts of trust, and benefit and cost factors. Journal of Strategic Information Systems, 2017. 26(2): p. 101-117.

[13] Gassmann, O. and E. Enkel, Towards a theory of open innovation: Three core process archetypes. 2004.

[14] Martins, T.C.M., P.H. de Souza Bermejo, and W.V.B. de Souza, Open innovation for citizen coproduction, in 4th International Conference on Electronic Government and the Information Systems Perspective, EGOVIS 2015, September 1-3, 2015. 2015. Valencia, Spain: Springer Verlag.

[15] Brasil, MEC vai premiar experiências de combate ao Aedes aegypti e de inovação tecnológica. 2018 [cited 2018 30-ago-2018].

[16] de Souza, W.V.B., et al., Planning the use of crowdstorming for public management: A case in the Ministry of Education of Brazil. 2014.

[17] dos Santos, A.C., et al., Open innovation and social participation: A case study in public security in Brazil, in International Conference on Electronic Government and the Information Systems Perspective. 2015. Springer.

[18] Mao, K., et al., A survey of the use of crowdsourcing in software engineering. Rn, 2015. 15(01).

[19] Christensen, I. and C. Karlsson, Open innovation and the effects of crowdsourcing in a pharma ecosystem. Journal of Innovation \& Knowledge, 2018.

[20] Soon, J.M. and I.S. Saguy, Crowdsourcing: A new conceptual view for food safety and quality. Trends in Food Science \& Technology, 2017. 66: p. 63-72.

[21] Peer, E., et al., Beyond the Turk: Alternative platforms for crowdsourcing behavioral research. Journal of Experimental Social Psychology, 2017. 70: p. 153-163.

[22] Paolacci, G., J. Chandler, and P.G. Ipeirotis, Running experiments on Amazon Mechanical Turk. 2010.

[23] Stewart, N., J. Chandler, and G. Paolacci,

Crowdsourcing samples in cognitive science. Trends in Cognitive Sciences, 2017.

[24] Buhrmester, M., T. Kwang, and S.D. Gosling, Amazon's Mechanical Turk: A new source of inexpensive, yet highquality, data? Perspectives on Psychological Science, 2011. 6(1): p. 3-5. 
[25] Chandler, J., P. Mueller, and G. Paolacci, Nonnaïveté among Amazon Mechanical Turk workers: Consequences and solutions for behavioral researchers. Behavior Research Methods, 2014. 46(1): p. 112-130.

[26] Ipeirotis, P.G., Analyzing the Amazon Mechanical Turk marketplace. XRDS: Crossroads, The ACM Magazine for Students, 2010. 17(2): p. 16-21.

[27] Schmidt, F.A., The good, the bad and the ugly: Why crowdsourcing needs ethics, in Third International

Conference on Cloud and Green Computing (CGC). 2013. IEEE.

[28] Bernstein, J. and M. Calamia, Characteristics of a mild traumatic brain injury sample recruited using Amazon's Mechanical Turk. PM\&R, 2018. 10(1): p. 45-55.

[29] Bunge, E., et al., Comparing Amazon Mechanical Turk with unpaid internet resources in online clinical trials. Internet Interventions, 2018. 12: p. 68-73.

[30] Tran, M., et al., Online recruitment and testing of infants with Mechanical Turk. Journal of Experimental Child Psychology, 2017. 156: p. 168-178.

[31] Rahman, M., et al., Smartphone-based hierarchical crowdsourcing for weed identification. Computers and Electronics in Agriculture, 2015. 113: p. 14-23.
[32] Ball, G.P., R. Shah, and K. Donohue, The decision to recall: A behavioral investigation in the medical device industry. Journal of Operations Management, 2018.

[33] West, J., et al., Open innovation: The next decade. 2014, Elsevier.

[34] Wise, S., R.A. Paton, and T. Gegenhuber, Value co-creation through collective intelligence in the public sector: A review of US and European initiatives. VINE, 2012. 42(2): p. 251-276.

[35] Linders, D., From e-government to we-government: Defining a typology for citizen coproduction in the age of social media. Government Information Quarterly, 2012. 29(4): p. 446-454.

[36] Surowiecki, J., A sabedoria das multidões. 2006: Editora Record.

\section{Acknowledgment}

The authors thank the National Council for Scientific and Technological Development (CNPq-Brasil) - Process 402789/2015-6 for financially supporting this study. 